Letter

\title{
Ocean Surface Wind Speed Retrieval Using Simulated RADARSAT Constellation Mission Compact Polarimetry SAR Data
}

\author{
He Fang ${ }^{1}$, William Perrie ${ }^{2}$, Guosheng Zhang ${ }^{3, * \mathbb{C}}$, Tao Xie ${ }^{4}$, Shahid Khurshid ${ }^{5} \mathbb{C}^{\text {, }}$ \\ Kerri Warner ${ }^{5}$, Jingsong Yang ${ }^{6}\left(\mathbb{B}\right.$ and Yijun $\mathrm{He}^{3}{ }^{(1)}$ \\ 1 Zhejiang Climate Centre, Hangzhou 310017, China \\ 2 Fisheries \& Oceans Canada, Bedford Institute of Oceanography, Dartmouth, NS B2Y 4A2, Canada \\ School of Marine Sciences, Nanjing University of Information Science and Technology, Nanjing 210044, China \\ 4 School of Remote Sensing and Geomatics Engineering, Nanjing University of Information Science and \\ Technology, Nanjing 210044, China \\ 5 Earth Applied Science \& Development Section Observation \& Geomatics, Meteorological Service of Canada, \\ Environment and Climate Change Canada, Ottawa, ON K1A 0H3, Canada \\ 6 State Key Laboratory of Satellite Ocean Environment Dynamics, Second Institute of Oceanography, \\ Ministry of Natural Resources, Hangzhou 310012, China \\ * Correspondence: zhanggs@nuist.edu.cn; Tel.: +86-25-5869-5692
}

Received: 5 July 2019; Accepted: 7 August 2019; Published: 10 August 2019

\begin{abstract}
We investigated the use of C-band RADARSAT Constellation Mission (RCM) synthetic aperture radar (SAR) for retrieval of ocean surface wind speeds by using four new channels (right circular transmit, vertical receive (RV); right circular transmit, horizontal receive (RH); right circular transmit, left circular transmit (RL); and right circular transmit, right circular receive (RR)) in compact polarimetry $(\mathrm{CP})$ mode. Using 256 buoy measurements collocated with RADARSAT-2 fine beam quad-polarized scenes, RCM CP data was simulated using a "CP simulator". Provided that the relative wind direction is known, our results demonstrate that wind speed can be retrieved from $\mathrm{RV}, \mathrm{RH}$ and RL polarization channels using existing C-band model (CMOD) geophysical model function (GMF) and polarization ratio (PR) models. Simulated RR-polarized radar returns have a strong linear relationship with speed and are less sensitive to relative wind direction and incidence angle. Therefore, a model is proposed for the RR-polarized synthetic aperture radar (SAR) data. Our results show that the proposed model can provide an efficient methodology for wind speed retrieval.
\end{abstract}

Keywords: wind speed; synthetic aperture radar (SAR); quad-polarized SAR; compact polarimetry

\section{Introduction}

Ocean surface winds are an important parameter for studies related to sea surface variables and processes in the lower atmospheric boundary layer, e.g., the water mass circulation and the coupling of atmospheric and oceanic systems. Therefore, to get a better understanding of air-sea interactions and to study processes that are relevant to ocean dynamics, we need to have large-scale, high-resolution, accurate ocean surface wind field data [1]. In recent decades, ocean surface wind data have been acquired by both passive and active satellites carrying altimeters, scatterometers, synthetic aperture radar (SAR), and radiometers. Among these techniques, SAR has become a popular technical means of monitoring sea surface parameters because of its capacity to operate in almost all-weather conditions, day or night, with high spatial resolution below a scale of $1 \mathrm{~km}$. And more importantly, given a sufficient quantity of images, the SAR technique has the potential to precisely assess coastal wind fields [2]. 
Ocean surface wind speed has been routinely retrieved by various SARs since the first SAR scenes became available in 1978. Many wind speed retrieval methods have been developed. The most commonly used wind speed retrieval model from SAR uses C-band normalized radar cross section (NRCS) in the form of a geophysical model function (GMF), called the C-band model (CMOD), which is related to the NRCS as a function of parameters such as relative wind direction, wind-relative radar azimuth, local incidence angle, and of course, wind speed, at 10-height above ocean level. In order to improve the accuracy of wind speed from vertical transmit, vertical receive (VV)-polarized images, a series of CMOD functions were developed, such as CMOD4, CMOD-IFR2, CMOD5, CMOD5.N, CMOD5.H, C-SARMOD2 and CMOD6 [3-9]. Recently, the latest CMOD function, named CMOD7, was proposed for application to inter-calibrate ERA(ASCAT)and ESCAT scatterometers [10].

However, no similar wind field retrieval models exist for horizontal transmit, horizontal receive $(\mathrm{HH})$-polarized SAR data. To remedy this difficulty, the polarization ratio (PR) was proposed to map the expected NRCS at VV-polarized mode to HH-polarized values for the same wind direction and speed. Thus, when these CMOD GMFs are applied to HH-polarized SAR images, various PR models are used to convert HH-NRCS to VV-NRCS before application for wind retrieval [11]. The modelled VV-polarized NRCS corresponding to the measured HH-polarized NRCS can be computed and then used in the CMOD GMFs in the normal manner.

In severe weather, SAR-measured wind speed increases with increasing co-polarized (VV-and HH-polarized) NRCS values, eventually reaching a maximum and then beginning to decrease for higher values of wind speed (probably for winds greater than $20 \mathrm{~m} / \mathrm{s}$ ). Saturation of the co-polarized NRCS can be a disadvantage for high wind speed retrieval from SAR images [12]. Thus, the co-polarized NRCS experiences saturation under high wind conditions, which may lead to ambiguous or double-valued wind speed values for SAR-retrieved winds. By comparison, recent study has shown that C-band cross-polarized (horizontal transmit, vertical receive (HV)- and vertical transmit, horizontal receive (VH)-polarized) ocean backscatter data are quite linear with respect to the wind speed, although they do in fact exhibit some dependence on relative wind direction and radar incidence angle $[13,14]$. More critically, wind speed retrieved data from cross-polarized SAR images do not appear to saturate for wind speeds greater than $25 \mathrm{~m} / \mathrm{s}$, as in co-polarized data. This phenomenon indicates that cross-polarized data can potentially be used to estimate high wind speed events, especially for hurricane-generated winds [15-17].

Wind speed retrieval via the quad-polarized channel are a mature technical achievement that has been widely validated in different SAR systems, such as Envisat ASAR [18], RADARSAT-1 [19], RADARSAT-2 [20] and Sentinal-1 [21]. However, there are also some shortcomings in the traditional polarimetric SAR system that still need to be further improved. On top of which, the limitation of conventional quad-polarized SAR systems is mainly the acquisition of SAR images with both wide swath coverage and high spatial resolution, and therefore insufficient wind data for operational use in terms of covering the vast global ocean. On account of these drawbacks, there is intense ongoing study of compact polarimetry (CP) for the remote sensing of Earth observations including oceanography because of its large spatial coverage and its diverse information content [22].

The C-band RADARSAT Constellation Mission (RCM) is the successor of RADARSAT-2 (RS-2) and the latest step in the evolution of the RADARSAT program. RCM was launched on 12 June 2019. The CP mode, which consists of a right-hand circular transmit and circular/linear receive signal, is a new RCM product [23]. RCM CP mode will provide four polarizations: right circular transmit, vertical receive $(R V)$, right circular transmit, horizontal receive $(R H)$, right circular transmit, left circular receive (RL), and right circular transmit, right circular receive (RR). Theoretically, the aforementioned four $C P$ polarizations is cross- or co-polarized in the conventional sense, since the received and transmitted polarization bases are different; therefore, these CP channels can be considered as containing a mixture of co- and cross-polarized linear NRCS [24]. Therefore, the launch of RCM is desirable, and the collected CP data in a variety of wide-swath imaging modes is well suited for use in ocean surface wind monitoring. 
In this study, 256 RCM CP SAR images are simulated from the fine-beam RADARSAT-2 (RS-2) quad-polarized SAR data by a "CP simulator". These SAR images are collocated to buoy observations. Section 2 describes the simulated RCM CP radar signals and collocated buoy-measured wind speeds. Section 3 gives the wind speed retrieval from simulated RV-, RH-, and RL-polarized data using existing CMOD GMFs and PR models, based on the relationship between CP and linear quad-polarization SAR data. Thus, a new wind speed retrieval model is proposed in Section 4, to estimated wind speed from RR-polarized SAR image data. Conclusions are given in Section 5. Next, based on the generated CP parameters, the potential ability of wind speed retrievals from RCM will be considered in ongoing studies.

\section{Materials}

\subsection{Buoy Data}

We obtained in situ observations from 9 buoys off the east and west coasts of Canada, which were paired with the accompanying collocated RADARSAT-2 fine-beam quad-polarized SAR images. All of the buoy observations were from Environment and Climate Change Canada (ECCC) between January 2009 and April 2011.The ECCC moored buoys provide the wind field data over an 8-min acquisition period each hour, wave parameters (significant wave height, dominant wave direction, and period), and sea surface meteorological parameters (air temperature, dew point temperature, sea surface pressure, and sea surface temperature). A summary of the buoys used in this paper, and their locations, is shown in Table 1.

Table 1. Detailed information on Environment and Climate Change Canada (ECCC) buoys.

\begin{tabular}{cccc}
\hline Area & Buoy Code & Latitude (deg) & Longitude (deg) \\
\hline & 46025 & $33.761 \mathrm{~N}$ & $119.049 \mathrm{~W}$ \\
Canada & 46145 & $54.37 \mathrm{~N}$ & $132.44 \mathrm{~W}$ \\
West & 46184 & $53.91 \mathrm{~N}$ & $138.85 \mathrm{~W}$ \\
Sea & 46208 & $52.52 \mathrm{~N}$ & $132.69 \mathrm{~W}$ \\
& 46204 & $51.38 \mathrm{~N}$ & $128.77 \mathrm{~W}$ \\
& 46004 & $50.93 \mathrm{~N}$ & $136.1 \mathrm{~W}$ \\
\hline Canada & 44139 & $44.24 \mathrm{~N}$ & $57.1 \mathrm{~W}$ \\
East & 44141 & $42.99 \mathrm{~N}$ & $57.96 \mathrm{~W}$ \\
Sea & 44140 & $42.87 \mathrm{~N}$ & $51.47 \mathrm{~W}$ \\
\hline
\end{tabular}

In addition, because the anemometers heights are approximately $5 \mathrm{~m}$ above sea surface level, the wind speeds measured by the buoys are considered to be the real wind speeds at $5 \mathrm{~m}$ height above the ocean surface. It is necessary to convert these buoy-measured wind speeds to values at $10 \mathrm{~m}$ height as neutral winds, using a wind profile algorithm [25]. The temporal separation between the buoy data and the SAR data is restricted to less than $30 \mathrm{~min}$. Because the SAR system is an active microwave sensor, the effects of the seasons and weather, day or nighttime conditions, are negligible.

\subsection{Simulating CP Data Using Quad-polarized SAR Images}

RCM was launched on 12 June 2019. Actual CP data is expected by October 2019, after validation and calibration tests are completed. Therefore, the present availability of CP RCM SAR data is limited to simulated CP mode data as generated by a "RCM CP simulator" used in previous studies. This simulator was developed by François Charbonneau of the Canada Centre for Remote Sensing, using quad-polarized SAR observation data as input data, such as the RS-2 fine-beam quad-polarized mode data $[26,27]$. The simulator generates corresponding SAR images at the planned noise equivalent sigma zero (NESZ) and spatial resolution of the desired RCM imaging modes. Thus, simulated RCM data will include three product modes: low noise mode, low resolution mode, and medium resolution mode. Table 2 gives an overview of the simulated RCM imaging modes in comparison to RS-2 modes. 
In this paper, we have 256 RS-2 fine-beam quad-polarized SAR images, which are processed by the $\mathrm{CP}$ simulator to create RCM low-noise mode data. The results of the generated $\mathrm{CP}$ configurations are used as "ground truth" in our study. Figure 1 shows an example of RS-2 fine-beam quad-polarized SAR images acquired on 8 November 2009 at 02:47:39 Coordinate Universal Time (UTC). These SAR images collocate with an ECCC buoy (\#46004, 50 $55^{\prime} 48^{\prime \prime} \mathrm{N} 136^{\circ} 6^{\prime} \mathrm{W}$ ) off the Canadian West Coast. The buoy-measured $10 \mathrm{~m}$ wind speed and direction are $9.74 \mathrm{~m} / \mathrm{s}$ and $283^{\circ}$ at $02: 30 \mathrm{UTC}$. The NRCS of the VV-, $\mathrm{HH}-, \mathrm{VH}-$, and HV-polarized images at buoy location are $-10.65 \mathrm{~dB},-12.47 \mathrm{~dB},-29.48$ $d B$, and $-29.17 \mathrm{~dB}$, respectively. Figure 2 presents the corresponding RCM CP mode SAR images generated from the $\mathrm{CP}$ simulator. The NRCS of the RV-, RH-, RL-, and RR-polarized images at buoy location are $-13.84 \mathrm{~dB},-12.72 \mathrm{~dB},-8.73 \mathrm{~dB}$ and $-20.64 \mathrm{~dB}$, respectively.
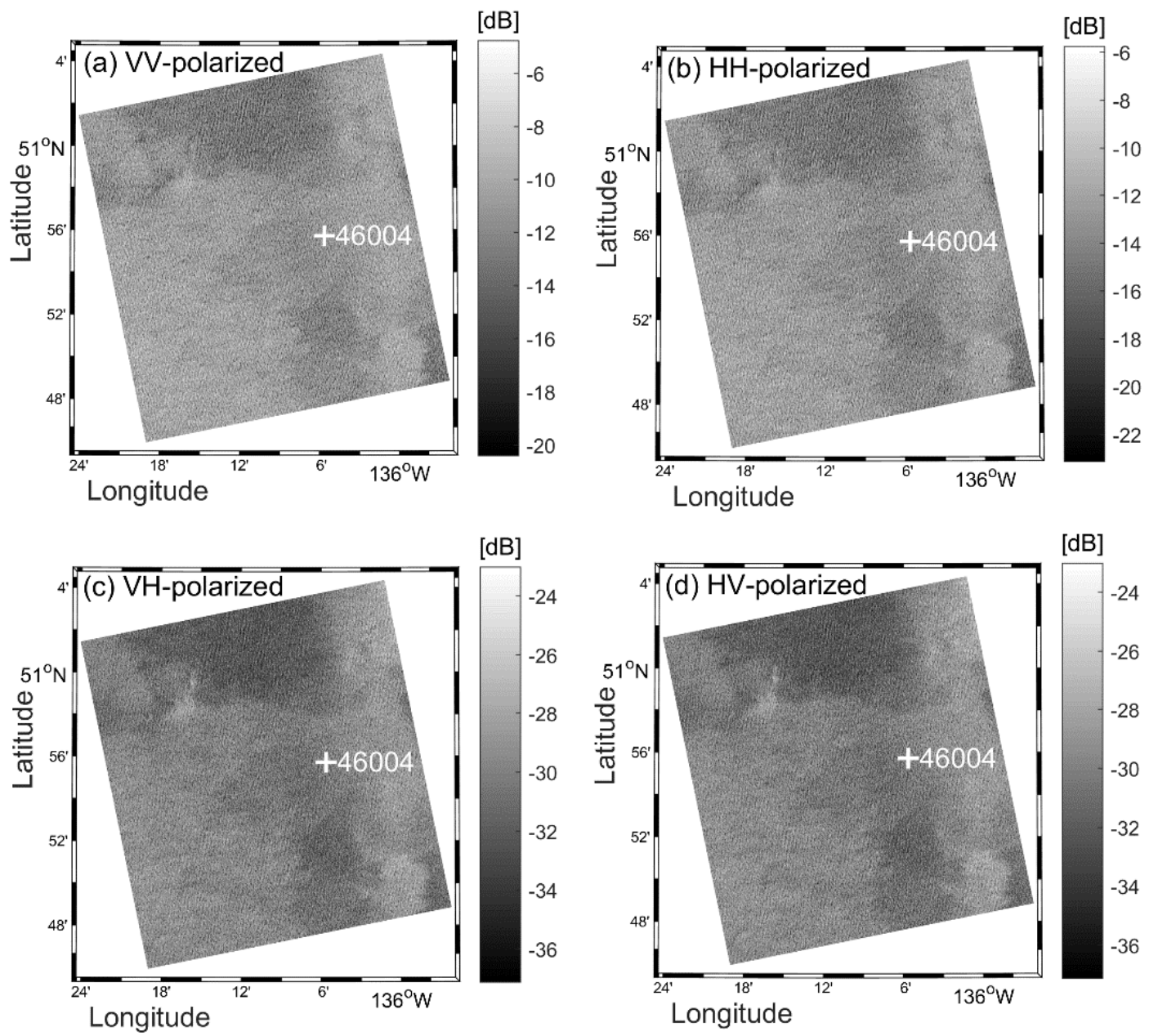

Figure 1. (a) VV-, (b) HH-, (c) VH- and (d) HV-polarized synthetic aperture radar (SAR) images off Canada's West Coast from RS-2 fine-beam quad-polarization mode data acquired on 8 November 2009, at 02:47:39 UTC, and the location of the ECCC buoy ( $\# 46004,50^{\circ} 55^{\prime} 48^{\prime \prime} \mathrm{N} 136^{\circ} 6^{\prime} \mathrm{W}$ ) collocated to the SAR images. RADARSAT-2 Data and Products from MacDonald, Dettwiler, and Associates Ltd. All Rights Reserved. 

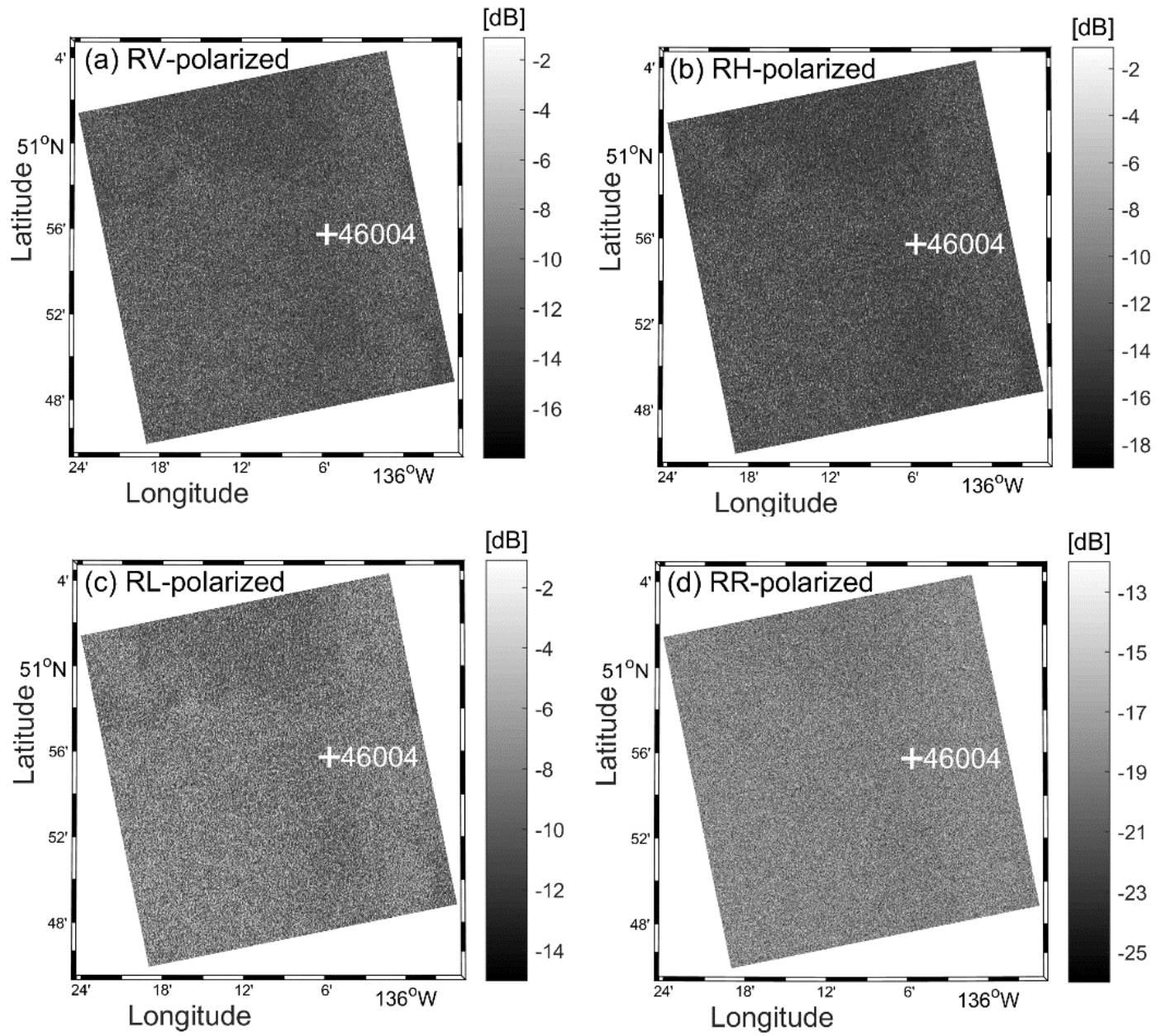

Figure 2. (a) RV-, (b) RH-, (c) RL- and (d) RR-polarized compact polarimetry SAR images generated from Figure 1 using the $\mathrm{CP}$ simulator.

Table 2. An overview of simulated RADARSAT Constellation Mission (RCM) image data from the compact polarimetry (CP) simulator and RADARSAT-2 (RS-2) data.

\begin{tabular}{cccc}
\hline Imaging Mode & Resolution $(\mathbf{m})$ & Swath Width $\mathbf{( k m )}$ & NESZ (dB) \\
\hline RCM medium-resolution & 50 & 350 & -22 \\
RCM low-noise & 100 & 350 & -25 \\
RCM low-resolution & 100 & 500 & -22 \\
RS-2 quad-polarization & 5 & 25 & -3 \\
\hline
\end{tabular}

\section{Methods}

Through analysis of the texture relationship between RS-2 linear fine-beam quad-polarization data and RCM CP SAR data, Geldsetzer et al. [27] demonstrated that the simulated NRCS of RV-polarized (or RH-polarized) images approximately equals half of that of the co-polarized (VV- or HH-polarized) images. Therefore, the co-polarized wind speed retrieval model can be employed for the compact polarized wind speed inversion.

The RV- and RH-polarized wind speed retrieval functions are supposed to be related to the co-polarized model as:

$$
\begin{gathered}
\sigma_{R V}^{0} \approx 0.5 \times \operatorname{MOD}\left(\theta, \varnothing, U_{10}\right) \\
\sigma_{R H}^{0} \approx 0.5 \times \operatorname{CMOD}\left(\theta, \varnothing, U_{10}\right) / \operatorname{PR}(\theta)
\end{gathered}
$$


Moreover, the RL-polarized NRCS can be derived from the RH and RV channels with some assumptions. Therefore, the relationship between RL- and co-polarized wind speed retrieval models as given by Geldsetzer et al. [27]:

$$
\sigma_{\mathrm{RL}}^{0} \approx 0.25 \times \operatorname{CMOD}\left(\theta, \varnothing, U_{10}\right) / \operatorname{PR}(\theta)+0.5 \sqrt{\operatorname{CMOD}\left(\theta, \varnothing, U_{10}\right)^{2} / \operatorname{PR}(\theta)}
$$

where $\sigma_{R V^{\prime}}^{0}, \sigma_{R H}^{0}$ and $\sigma_{R L}^{0}$ are the RV-, RH-, and RH-polarized NRCS, respectively; $\theta$ is the radar incidence angle; $\varnothing$ is the relative wind direction; and $U_{10}$ is the wind speed at $10-\mathrm{m}$ reference height.

In recent decades, a series of CMOD functions were originally developed for global coverage scatterometer wind field retrievals in C-band. Later, the CMOD models have been successfully applied to wind field retrievals from C-band SAR data. Among these CMOD functions, CMOD4, CMOD-IFR2, CMOD5 and CMOD5.N are widely used for wind speed retrieval from SAR images. The latest CMOD function, CMOD7, has been proposed in several steps as a successor of CMOD5.N [10]. However, the usage of CMOD7 is limited to scatterometer data till now. Therefore, the applicability of CMOD7 for C-band SAR data remains to be further verified. Zhang et al $[21,28]$ retrieved wind speed based on CMOD4, CMOD-IFR2, CMOD5, and CMOD5.N off the U.S. coasts, and the results suggested that CMOD5 GMF is the optimal function of these formulations. In this paper, we selected CMOD5 GMF as the RV-polarized wind speed retrieval model, and the general form is described as follows:

$$
\sigma_{V V}^{0}=B_{0}\left(\theta, U_{10}\right)\left[1+B_{1}\left(\theta, U_{10}\right) \cos \varnothing+B_{1}\left(\theta, U_{10}\right) \cos 2 \varnothing\right]^{1.6} .
$$

Here, $\sigma_{V V}^{0}$ is the VV-polarized NRCS; $\theta$ is the radar incidence angle; $\varnothing$ is the relative wind direction, and $U_{10}$ is the wind speed at $10-\mathrm{m}$ reference height; $B_{0}, B_{1}$, and $B_{2}$ are functions of $U_{10}$ and $\theta$.

However, as noted in the introduction, no similar well-developed models exist for HH-polarized wind speed retrieval, and the commonly used method has been to convert the HH-polarized NRCS to VV-polarized NRCS using a PR model, and then to compute the wind speeds using the CMOD GMFs. The PR model can be written as follows:

$$
\mathrm{PR}=\frac{\sigma_{\mathrm{VV}}^{0}}{\sigma_{\mathrm{HH}}^{0}}
$$

where $\sigma_{\mathrm{HH}}^{0}$ and $\sigma_{\mathrm{VV}}^{0}$ are the NRCSs of $\mathrm{HH}$ and VV polarizations, respectively. In this paper, six PR models, denoted by E1996 [29], T1998 [30], H2000 [31], V2000 [13], M2005 [32], and Z2011 [33], were used to retrieve wind speed for RH- and RL-polarized SAR data. Figure 3 shows that the PR values from the above models increase rapidly with increasing incidence angles.

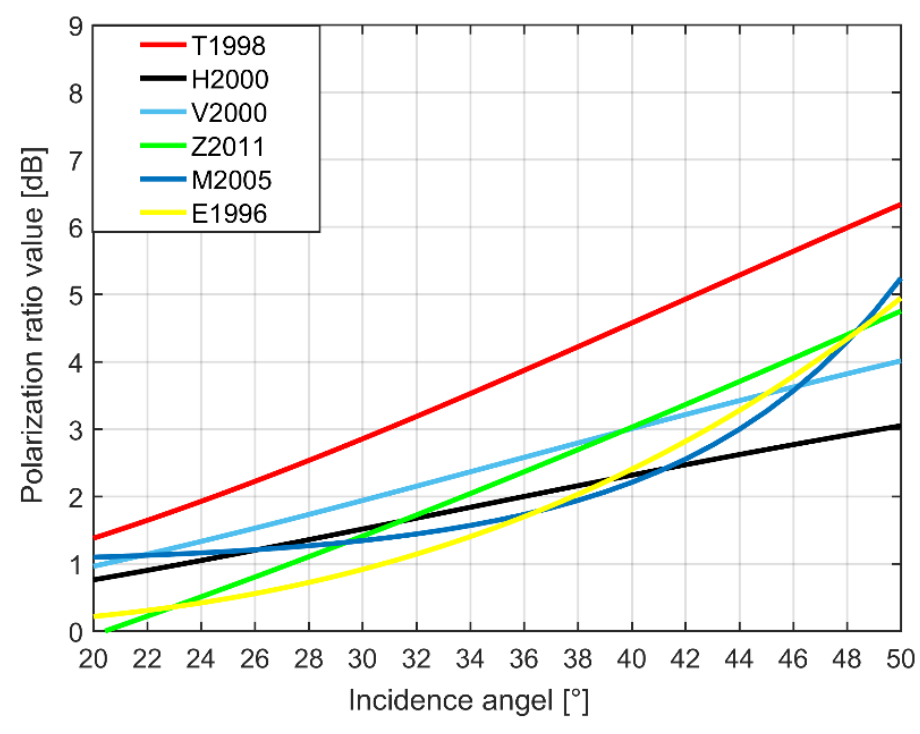

Figure 3. Polarization ratio formulations from the literature as a function of radar incidence angle. 


\section{Results}

\subsection{NRCS versus Buoy Measuremens}

To investigate the potential capacity of wind speed retrieval from simulated RCM CP data, we first make an analysis of NRCS quality in each polarization using buoy-measured wind speeds. In Figure 4, we show that the NRCS values in each polarization increase with increasing buoy wind speed measurements. This characteristic is the foundation of the wind speed retrieval methodology for simulated RCM CP data. Moreover, the behavior of NRCSs in RR polarization data is quite different from those of the RV, RH and RL polarizations. Similar to the RS-2 cross-polarized (VHand HV-polarized) SAR data, the simulated NRCSs of RCM RR-polarized data exhibit a strong linear relationship with the buoy wind speed observations.
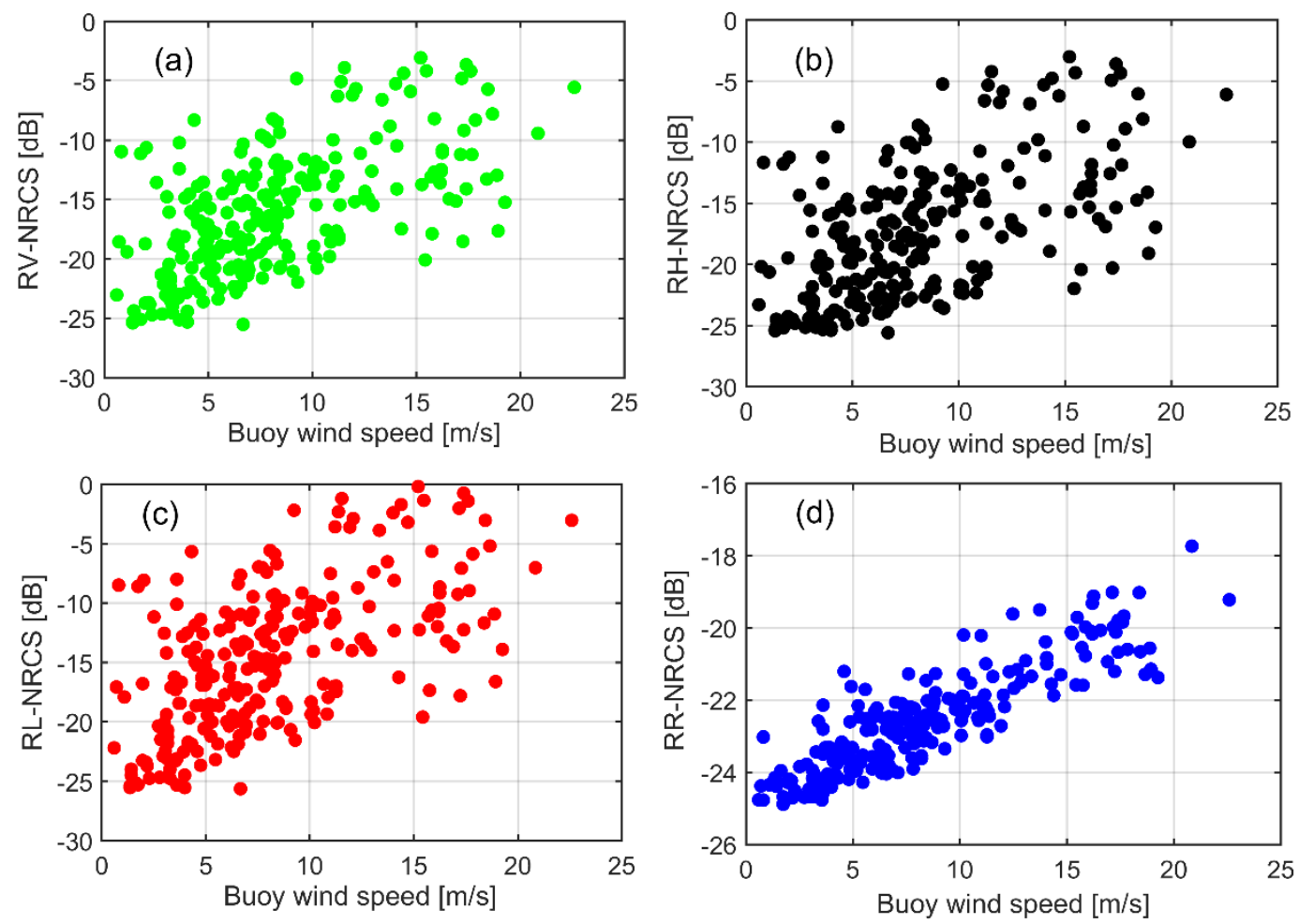

Figure 4. Simulated RCM CP radar returns vs buoy-measured wind speeds: (a) RV-polarization, (b) RH-polarization, (c) RL-polarization and (d) RR-polarization.

\subsection{Wind Speed Retrieval}

Through the above discussion, we use CMOD5 GMF to retrieve wind speeds from simulated RV-polarized SAR images. Based on the results between retrieved wind speeds and buoy-measured wind speeds, we first test the suitability of the CMOD5 function for RV-polarized wind speed retrieval.

Then, the simulated RH- and RL-polarized NRCSs are converted into RV-polarized NRCS using various PR models. The CMOD5 function with different PR models is then used to retrieve the RHand RL-polarized wind speeds by the converted corresponding NRCS.

Figure 5 shows the relation between SAR-retrieved wind speeds and buoy-measured wind speeds from 256 simulated RV-polarized SAR images. The root mean square errors (RMSEs) of SAR-retrieved wind speed is $2.42 \mathrm{~m} / \mathrm{s}$, and the correlation coefficient is 0.82 , which are statistically significant at the 99.9\% significance level. The results demonstrate that CMOD5 has better applicability for simulated C-band RV-polarized SAR data. 


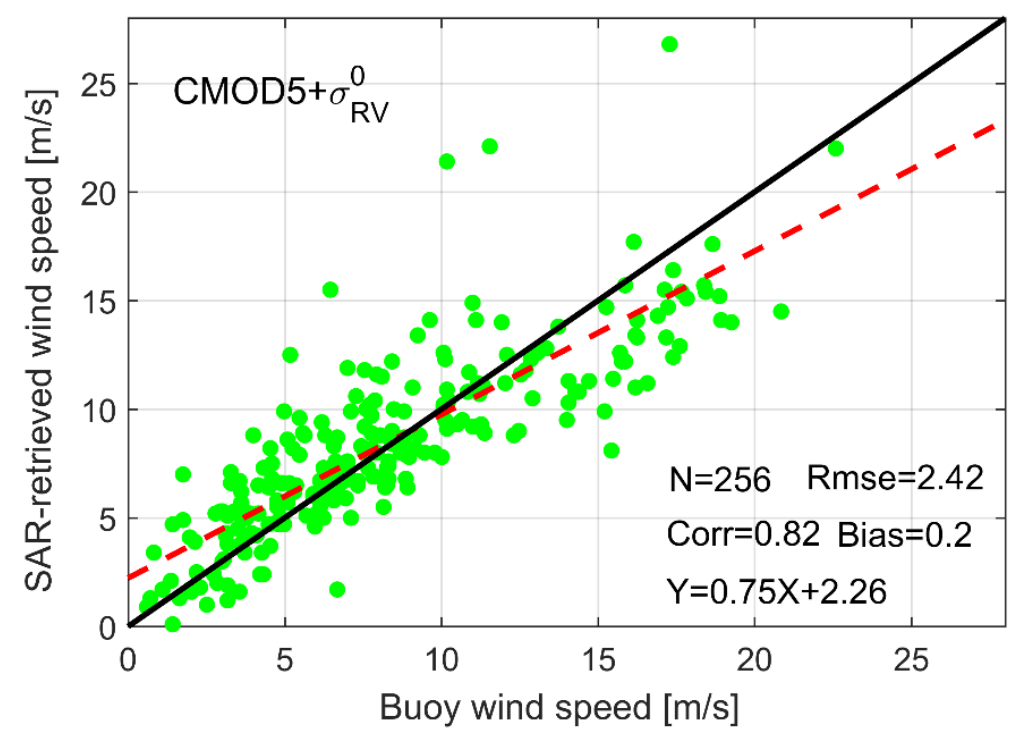

Figure 5. SAR-retrieved wind speeds from simulated RV-polarized SAR data by C-band model (CMOD) 5 function versus the buoy-measured wind speeds. The dashed line represents nonlinear least-square fit between SAR-retrieved wind speeds and buoy measurements. The same below.

For simulated RH-polarized SAR data, we select CMOD5 function with E1996, T1998, H2000, V2000, M2005, and Z2011 PR models to estimate wind speed based on Equation (2). Figure 6 shows the relation between SAR-retrieved wind speeds and buoy-measured wind speeds from 256 simulated RH-polarized SAR images. The RMSEs of these SAR-retrieved wind speeds are $3.14 \mathrm{~m} / \mathrm{s}$ (CMOD5+E1996), 3.21 m/s (CMOD5+T1998), 4.08 m/s (CMOD5+H2000), 3.3 m/s (CMOD5+V2000), $5.49 \mathrm{~m} / \mathrm{s}$ (CMOD5+M2005), and $2.48 \mathrm{~m} / \mathrm{s}$ (CMOD5+Z2011), respectively. These results demonstrate that the Z2011 PR model has the smallest RMSE, which means that the optimal PR model for wind speed retrieval from RH-polarized data is Z2011. Moreover, the results also show that the accuracy of the retrieved wind speeds from the Z2011 PR model can significantly outperform the others. The potential reason of this phenomenon is that the Z2011 model is based on RS-2 fine-beam quad-polarization images, which are the same as those used in this study.

Similarly, we use CMOD5 function with E1996, T1998, H2000, V2000, M2005, and Z2011 PR functions to estimate RL-polarized wind speed from Equation (3). Figure 7 shows the scatter plot between SAR-retrieved wind speeds from simulated RL-polarized SAR images and buoy measurements. The RMSEs of SAR-retrieved wind speeds are $2.72 \mathrm{~m} / \mathrm{s}$ (CMOD5+E1996), $2.58 \mathrm{~m} / \mathrm{s}$ (CMOD5+T1998), $2.95 \mathrm{~m} / \mathrm{s}$ (CMOD5+H2000), $2.63 \mathrm{~m} / \mathrm{s}$ (CMOD5+V2000), $3.39 \mathrm{~m} / \mathrm{s}$ (CMOD5+M2005), and $2.31 \mathrm{~m} / \mathrm{s}$ (CMOD5+Z2011). These results show that the CMOD5+Z2011 has the smallest RMSE. Therefore, the optimal PR function for wind speed retrieval from RL-polarized data is Z2011. 

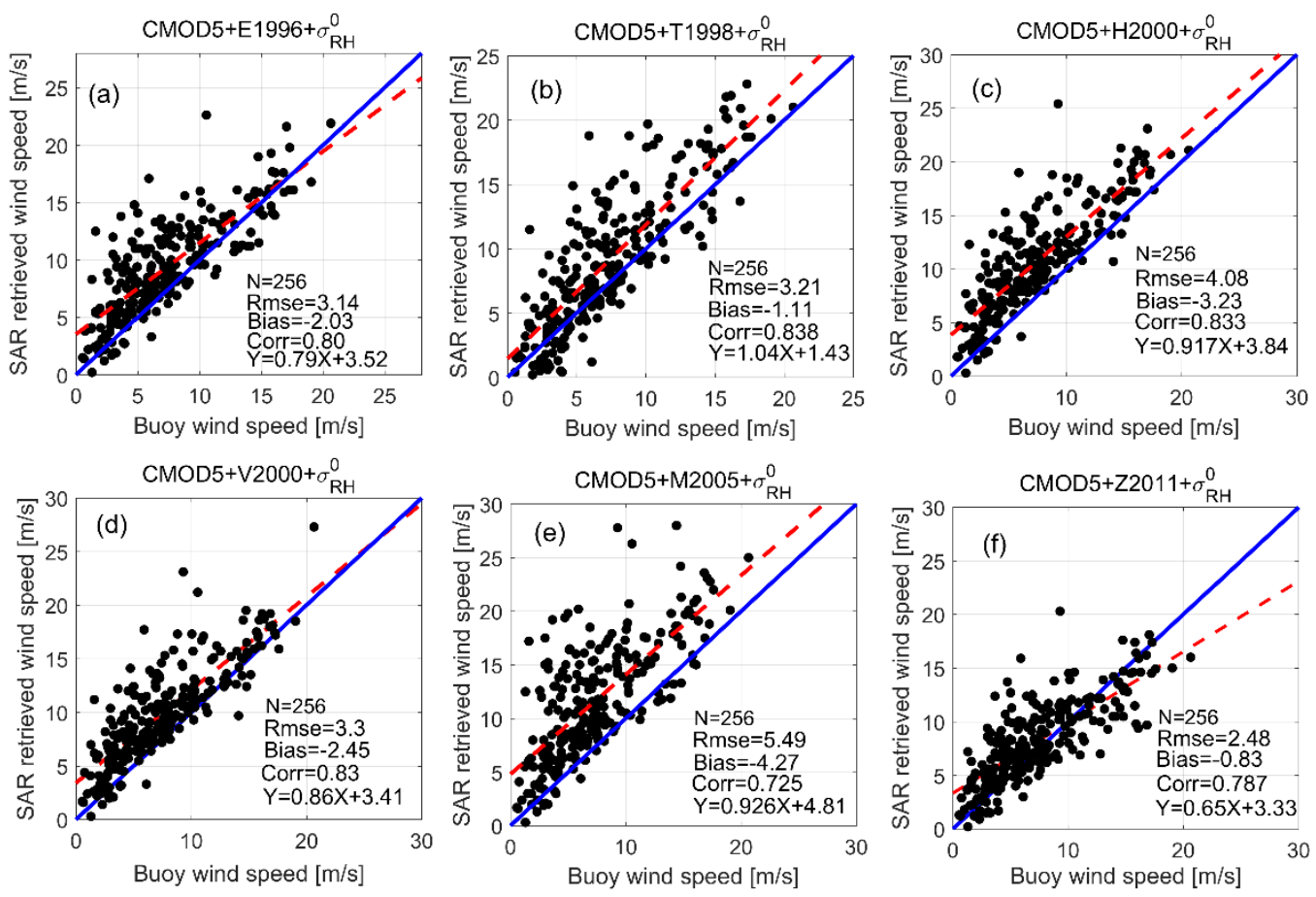

Figure 6. SAR-retrieved wind speeds from simulated RH-polarized SAR data by CMOD5 function with (a) E1996, (b) T1998, (c) H2000, (d) V2000, (e) M2005, and (f) Z2011 versus the buoy-measured wind speeds.
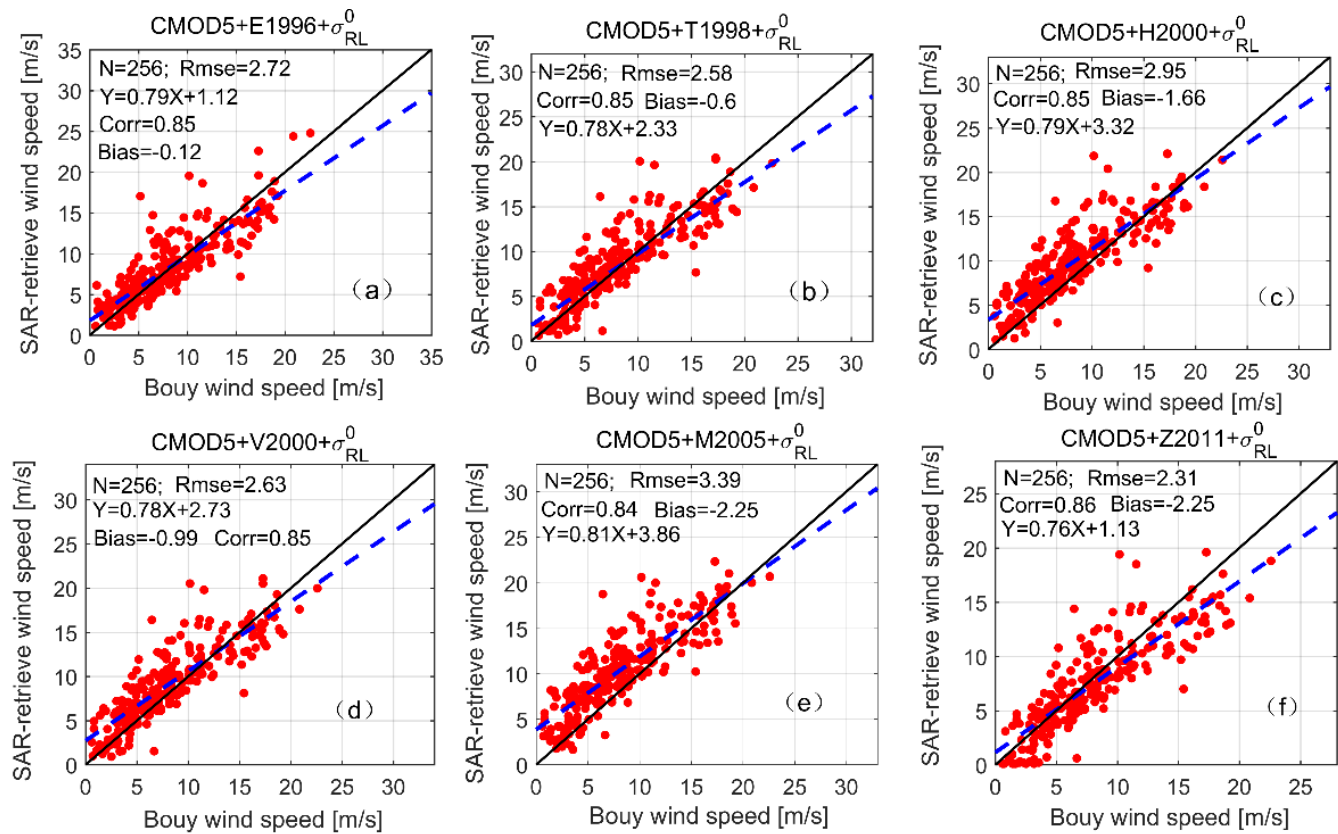

Figure 7. SAR-retrieved wind speeds from simulated RL-polarized SAR data by CMOD5 function with (a) E1996, (b) T1998, (c) H2000, (d) V2000, (e) M2005, and (f) Z2011 versus the buoy-measured wind speeds.

\section{Discussion}

According to CP theory, RR-polarized SAR data can be derived from the RV and RH channels with some assumptions. However, the fact is that there is no good texture relationship between RR- polarization and linear quad-polarization. In order to investigate the potential capacity for observations of wind speed from simulated RR-polarized SAR images, we first present an analysis 
of the relationship between RR-polarized NRCS and relative wind direction. In Figure 8a, we show a scatter plot of simulated NRCSs to relative wind direction, in RV, RH, RL and RR polarizations. In order to see the variations clearly, we divide wind directions into four groups $\left(0 \sim 90^{\circ}, 90 \sim\right.$ $180^{\circ}, 180 \sim 270^{\circ}$ and $270 \sim 360^{\circ}$ ) and calculate average values in each group. In particular, we also compute the corresponding average values for NRCSs for each group. Figure $8 \mathrm{~b}$ shows the variations of simulated NRCSs and wind directions for each group in RV, RH, RL and RR polarization. Clearly, the NRCSs of RR polarization are less sensitive to the wind directions, which is different from the other three polarizations.
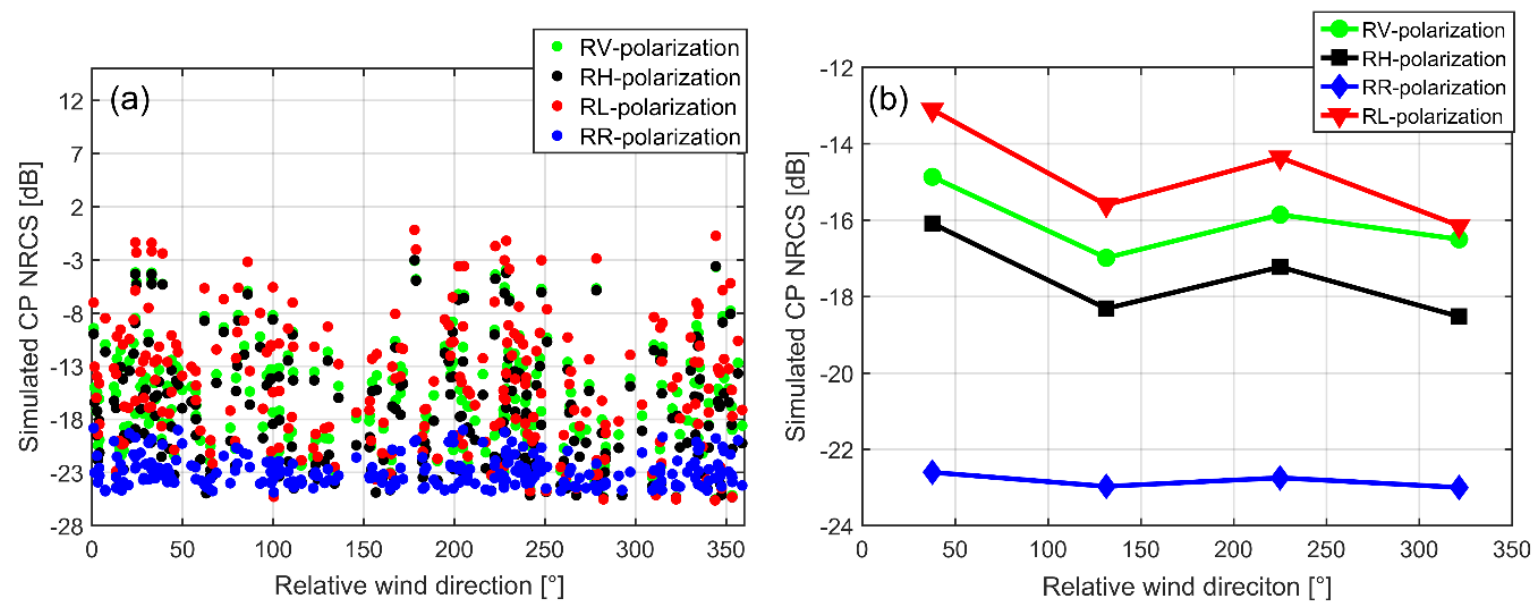

Figure 8. (a) Scatted plot of simulated RCM normalized radar cross sections (NRCSs) in RV, RH, RL and RR polarizations versus relative wind directions. (b) Variations of the average of NRCSs in RV, RH, RL and RR polarizations for four groups $\left(0 \sim 90^{\circ}, 90 \sim 180^{\circ}, 180 \sim 270^{\circ}\right.$ and $\left.270 \sim 360^{\circ}\right)$ versus relative wind directions.

Moreover, as shown in Figure 9, we also quantitatively investigate the variations of simulated NRCS values with radar incidence angles in RV, RH, RL and RR polarizations. The RV-, RH-, and RL-polarized NRCSs tend to decrease with increasing incidence angles. However, the behaviors of RR-polarized NRCSs are less sensitive to the incidence angle, which is significantly different from the characteristics of the other three polarizations. Similar to the RS- 2 cross-polarization, the simulated RCM NRCSs in RR polarizations are essentially independent of incidence angle and wind direction (see Figure 8b) but reveal a strong linear relationship with the wind speeds (see Figure 4d). A C-band RCM RR-polarized (RCM-RR) wind speed retrieval model relating RR-polarized NRCS to the wind speed at 10-m height is proposed using simulated RCM CP mode SAR images and buoy-measured wind speed, via a nonlinear least-square method. The RCM-RR model is

$$
\sigma_{R R}^{0}=0.2732 \times U_{10}-25.087
$$

where $\sigma_{R R}^{0}$ is the VV-polarized NRCS and $U_{10}$ is the wind speed at 10-m reference height. 


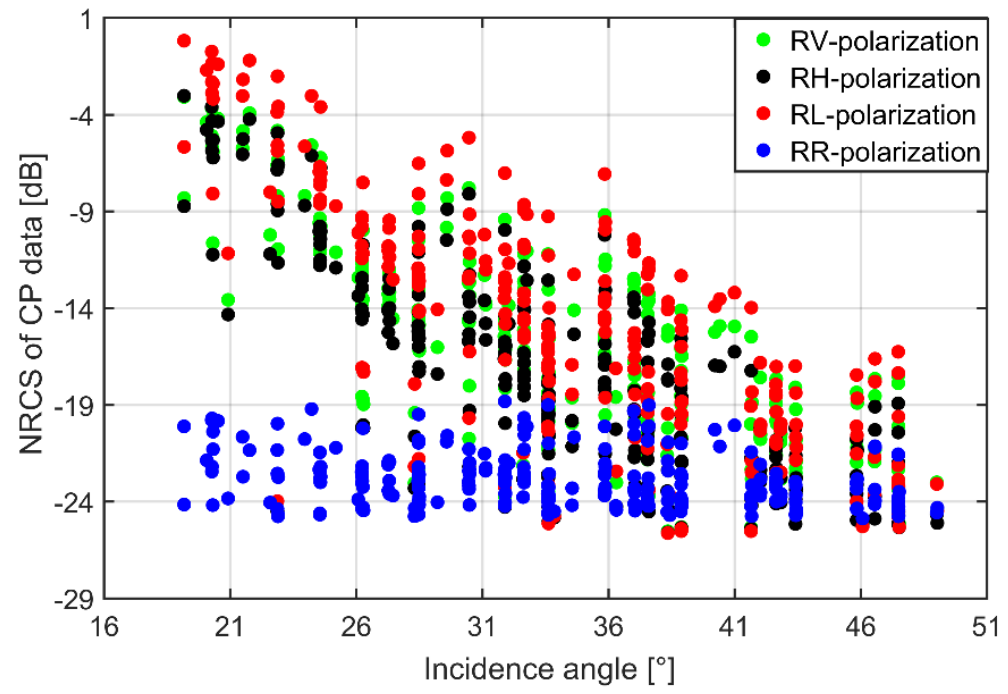

Figure 9. Simulated NRCSs versus radar incidence angle in RV, RH, RL and RR polarizations.

In the next test, we use the RCM-RR model to retrieve wind speeds based on 256 simulated RR-polarized SAR images. In Figure 10, the RCM-RR retrieved wind speeds are found to be in good agreement with buoy-measured wind speed, with a RMSE of $2.16 \mathrm{~m} / \mathrm{s}$ and a correlation coefficient of 0.91 .

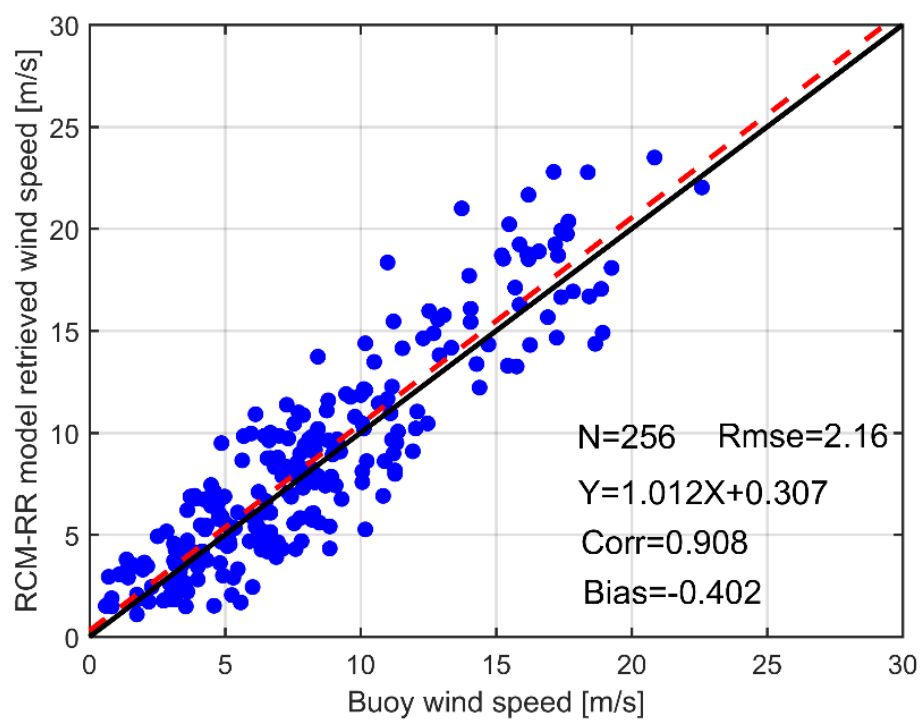

Figure 10. SAR-retrieved wind speeds from simulated RR-polarized SAR data by RCM-RR function versus the buoy-measured wind speeds.

\section{Conclusions}

The Canadian RADARSAT Constellation Mission (RCM) is the next step in the evolution of the RADARSAT program and the successor of RADARSAT-2. Although RCM was launched on 12 June 2019, validation and calibration tests will require about four months before observed compact polarimetry $(\mathrm{CP})$ data are available for studies about marine winds. $\mathrm{CP}$ data is different from the conventional polarimetry SAR data; the potential capability for wind speed retrieval from the new $\mathrm{CP}$ data is an important question.

In this paper, 256 CP SAR images are generated by a "CP simulator", which uses the fine-beam RS-2 quad-polarized SAR data as input data. Based on the texture relationship between RS-2 linear polarizations and $\mathrm{CP}, \mathrm{RV}-$-, RH-, and RL-polarized, wind speed can be estimated by using CMOD 
GMF and PR models. The retrieved wind speed from RV-polarized data using the CMOD5 function are found to be in good agreement with buoy-measured wind speeds, with a RMSE of $2.42 \mathrm{~m} / \mathrm{s}$. For RH-and RL-polarized wind speed retrieval, the CMOD5 function with Z2011 PR model are recommended as the optimal combination, with an RMSE of $2.48 \mathrm{~m} / \mathrm{s}$ (RH-polarized) and $2.31 \mathrm{~m} / \mathrm{s}$ (RL-polarized), respectively.

For RR-polarized SAR data, we found that the relationship for NRCS in RR polarization is strongly linear with respect to wind speed and less sensitive to dependence on relative wind direction and angle incidence angle. Therefore, a RR-polarized wind speed retrieval model, denoted RCM-RR, is developed in this paper. The RCM-RR retrieved wind speeds are found to be in good agreement with buoy-measured wind speeds, with an RMSE of $2.16 \mathrm{~m} / \mathrm{s}$.

In general, the relationship between ocean surface wind speeds and RCM CP mode radar signals has important implications for meteorological and oceanographic studies. Although the current availability of compact polarimetric SAR images is limited, once calibration and validation tests are completed by late 2019, application of CP observations for wind speed retrieval should become a viable new alternative.

Author Contributions: The first author of this paper, H.F., wrote the manuscript. G.Z. conceived and designed the experiments. H.F. and G.Z. performed the experiments. T.X., J.Y., and Y.H. supervised the work. S.K. and K.W. supported the data. W.P. reviewed, edited, and provided valuable suggestions and inputs for the final manuscript. H.F. and W.P. wrote the paper.

Funding: This work was supported by the National Key R\&D Program of China (2018YFC1506404 and 2016YFC1401007), the National Natural Science Foundation of China project (41776181), the National Natural Science Youth Foundation of China (41706193), the Canadian Space Agency DUAP Program "Winds from SAR" RCM Readiness Project, and the Canadian Office of Energy Research and Development, Canadian Space Agency SWOT Program, and The Startup Foundation for Introducing Talent of NUIST.

Acknowledgments: The authors thank the Canadian Space Agency for providing RADARSAT-2 data, NOAA NDBC for supplying buoy data (http://www.ndbc.noaa.gov/).

Conflicts of Interest: The authors declare no conflict of interest.

\section{References}

1. Skrunes, S.; Brekke, C.; Jones, C.E.; Espeseth, M.M.; Holt, B. Effect of wind direction and incidence angle on polarimetric SAR observations of slicked and unslicked sea surfaces. Remote Sens. Environ. 2018, 213, 73-91. [CrossRef]

2. Fang, H.; Xie, T.; Perrie, W.; Zhao, L.; He, Y. Ocean Wind and Current Retrievals Based on Satellite SAR Measurements in Conjunction with Buoy and HF Radar Data. Remote Sens. 2017, 9, 1321. [CrossRef]

3. Stoffelen, A.; Anderson, D. Scatterometer data interpretation: Estimation and validation of the transfer function CMOD4. J. Geophys. Res. Oceans 1997, 102, 5767-5780. [CrossRef]

4. Quilfen, Y.; Chapron, B.; Elfouhaily, T.; Katsaros, K.; Tournadre, J. Observation of tropical cyclones by high-resolution scatterometry. J. Geophys. Res. Oceans 1998, 103, 7767-7786. [CrossRef]

5. Hersbach, H.; Stoffelen, A.; de Haan, S. An improved C-band scatterometer ocean geophysical model function: CMOD5. J. Geophys. Res. Oceans 2007, 112. [CrossRef]

6. Hersbach, H. Comparison of C-band scatterometer CMOD5. N equivalent neutral winds with ECMWF. J. Atmos. Ocean. Technol. 2010, 27, 721-736. [CrossRef]

7. Soisuvarn, S.; Jelenak, Z.; Chang, P.S.; Alsweiss, S.O.; Zhu, Q. CMOD5.H-A High Wind Geophysical Model Function for C-Band Vertically Polarized Satellite Scatterometer Measurements. IEEE Trans. Geosci. Remote Sens. 2013, 51, 3744-3760. [CrossRef]

8. Yiru, L.; Biao, Z.; William, P.; Aurelien, M.A.; Xiaofeng, L.; He, W. A C-Band Geophysical Model Function for Determining Coastal Wind Speed Using Synthetic Aperture Radar. IEEE J. Sel. Top. Appl. Earth Obs. Remote Sens. 2018, 11, 2417-2428.

9. Elyouncha, A.; Neyt, X.; Stoffelen, A.; Verspeek, J. Assessment of the corrected CMOD6 GMF using scatterometer data. In Remote Sensing of the Ocean, Sea Ice, Coastal Waters, and Large Water Regions 2015; International Society for Optics and Photonics: Bellingham, WA, USA, 2015. 
10. Stoffelen, A.; Verspeek, J.A.; Vogelzang, J.; Verhoef, A. The CMOD7 Geophysical Model Function for ASCAT and ERS Wind Retrievals. IEEE J. Sel. Top. Appl. Earth Obs. Remote Sens. 2017, 10, 2123-2134. [CrossRef]

11. Bergeron, T.; Bernier, M.; Chokmani, K.; Lessard-Fontaine, A.; Lafrance, G.; Beaucage, P. Wind Speed Estimation Using Polarimetric RADARSAT-2 Images: Finding the Best Polarization and Polarization Ratio. IEEE J. Sel. Top. Appl. Earth Obs. Remote Sens. 2011, 4, 896-904. [CrossRef]

12. Fernandez, D.E.; Carswell, J.R.; Frasier, S.; Chang, P.S.; Black, P.G.; Marks, F.D. Dual-polarized C- and Ku-band ocean backscatter response to hurricane-force winds. J. Geophys. Res. Oceans 2006, 111. [CrossRef]

13. Vachon, P.W.; Wolfe, J. C-band cross-polarization wind speed retrieval. IEEE Trans. Geosci. Remote Sens. Lett. 2011, 8, 456-458. [CrossRef]

14. Zhang, B.; Perrie, W.; Vachon, P.W.; Li, X.; Pichel, W.G.; Guo, J.; He, Y. Ocean vector winds retrieval from C-band fully polarimetric SAR measurements. IEEE Trans. Geosci. Remote Sens. 2012, 50, 4252-4261. [CrossRef]

15. Shen, H.; Perrie, W.; He, Y.; Liu, G. Wind speed retrieval from VH dual-polarization RADARSAT-2 SAR images. IEEE Trans. Geosci. Remote Sens. 2014, 52, 5820-5826. [CrossRef]

16. Zhang, B.; Perrie, W.; Zhang, J.A.; Uhlhorn, E.; He, Y. High-Resolution Hurricane Vector Winds from C-Band Dual-Polarization SAR Observations. J. Atmos. Ocean. Technol. 2014, 31, 272-286. [CrossRef]

17. Zhang, G.; Li, X.; Perrie, W.; Hwang, A.; Zhang, B.; Yang, X. A Hurricane Wind Speed Retrieval Model for C-Band RADARSAT-2 Cross-Polarization ScanSAR Images. IEEE Trans. Geosci. Remote Sens. 2017, 55, 4766-4774. [CrossRef]

18. Yang, X.; Li, X.; Pichel, W.G.; Li, Z. Comparison of Ocean Surface Winds from ENVISAT ASAR, MetOp ASCAT Scatterometer, Buoy Measurements, and NOGAPS Model. IEEE Trans. Geosci. Remote Sens. 2011, 49, 4743-4750. [CrossRef]

19. Vachon, P.W.; Dobson, F.W. Wind retrieval from RADARSAT SAR images: Selection of a suitable C-band HH polarization wind retrieval model. Can. J. Remote Sens. 2000, 26, 306-313. [CrossRef]

20. Fang, H.; Xie, T.; Perrie, W.; Zhang, G.; Yang, J.; He, Y. Comparison of C-Band Quad-Polarization Synthetic Aperture Radar Wind Retrieval Models. Remote Sens. 2018, 9, 1321. [CrossRef]

21. Zhang, K.; Xu, X.; Han, B.; Mansaray, L.; Guo, Q.; Huang, J. The Influence of Different Spatial Resolutions on the Retrieval Accuracy of Sea Surface Wind Speed with C-2PO Models Using Full Polarization C-Band SAR. IEEE Trans. Geosci. Remote Sens. 2017, 55, 5015-5025. [CrossRef]

22. Souyris, J.C.; Imbo, P.; Fjortoft, R.; Mingot, S.; Lee, J.S. Compact polarimetry based on symmetry properties of geophysical media: The pi/4 mode. IEEE Trans. Geosci. Remote Sens. 2005, 43, 634-646. [CrossRef]

23. Guosheng, Z.; William, P.; Biao, Z.; Shahid, K.; Kerri, W. Semi-empirical ocean surface model for compact-polarimetry mode SAR of RADARSAT Constellation Mission. Remote Sens. Environ. 2018, $217,52-60$.

24. Raney, R. Hybrid-polarity SAR architecture. IEEE Trans. Geosci. Remote Sens. 2007, 45, 3397-3404. [CrossRef]

25. Liu, W.T.; Xie, X.; Tang, W. Scatterometer's Unique Capability in Measuring Ocean Surface Stress. In Oceanography from Space; Springer: Dordrecht, The Netherlands, 2010.

26. Charbonneau, F.J.; Brisco, B.; Raney, R.K.; Mcnairn, H.; Liu, C.; Vachon, P.W. Compact polarimetry overview and applications assessment. Can. J. Remote Sens. 2010, 36, S298-S315. [CrossRef]

27. Geldsetzer, T.; Charbonneau, F.; Arkett, M.; Zagon, T. Ocean wind study using simulated RCM compact-polarimetry SAR. Can. J. Remote Sens. 2015, 41, 418-430. [CrossRef]

28. Zhang, K.; Huang, J.; Xu, X.; Guo, Q.; Chen, Y.; Mansaray, L.; Li, Z.; Wang, X. Spatial Scale Effect on Wind Speed Retrieval Accuracy Using Sentinel-1 Copolarization SAR. IEEE Trans. Geosci. Remote Sens. Lett. 2018, 15, 882-886. [CrossRef]

29. Elfouhaily, T. Physical modeling of electromagnetic backscatter from the ocean surface; Application to retrieval of wind fields and wind stress by remote sensing of the marine atmospheric boundary layer. In Dépt. d'Océanogr. Spatiale, l'Inst. Français Rec; l’Exploitation Mer (IFREMER): Plouzane, France, 1997.

30. Thompson, D.R.; Elfouhaily, T.M.; Chapron, B. Polarization ratio for microwave backscattering from the ocean surface at low to moderate incidence angles. In Proceedings of the 1998 IEEE International Geoscience and Remote Sensing, Seattle, WA, USA, 6-10 July 1998; Volume 3, pp. 1671-1673.

31. Horstmann, J.; Koch, W.; Lehner, S.; Tonboe, R. Wind retrieval over the ocean using synthetic aperture radar with C-band HH polarization. IEEE Trans. Geosci. Remote Sens. 2000, 38, 2122-2131. [CrossRef] 
32. Mouche, A.A.; Hauser, D.; Daloze, J.F.; Guerin, C. Dual-polarization measurements at C-band over the ocean: Results from airborne radar observations and comparison with ENVISAT ASAR data. IEEE Trans. Geosci. Remote Sens. 2005, 43, 753-769. [CrossRef]

33. Zhang, B.; Perrie, W.; He, Y. Wind speed retrieval from RADARSAT-2 quad-polarization images using a new polarization ratio model. J. Geophys. Res. Oceans 2011, 116. [CrossRef] 